\title{
"WHEN THE SUN GOES DOWN": MELOPEIA E TRANSCRIAÇÃO EM ON THE ROAD DE JACK KEROUAC
}

\author{
Diana Junkes $\underline{1}$ \\ 1Universidade Federal de São Carlos, São Carlos, São Paulo, Brasil \\ Luiz Carlos de Brito Rezende 2 \\ 22Universidade de São Paulo, São Paulo, São Paulo, Brasil \\ Ivan Pérsio de Arruda Campos ${ }^{3}$ \\ ㄴUniversidade Paulista, São Paulo, São Paulo, Brasil
}

\begin{abstract}
Resumo: Este artigo tem como objetivo apresentar uma transcriação eficaz do parágrafo final de On the road de Jack Kerouac, que recupere a melopeia presente no original, usualmente desconsiderada ou não percebida em muitas das traduções desse texto para outras línguas. Mobilizam-se aqui, para fazê-lo, as contribuições à teoria da tradução oferecidas por Haroldo de Campos em inúmeros artigos, ensaios e conferências, ao longo de quarenta anos. Após breve apresentação do livro, o artigo faz um survey conceitual do pensamento haroldiano sobre a tradução, em seguida propõe a transcriação do trecho da obra de Kerouac referido acima, com ênfase no trabalho recriador, e cotejando as soluções propostas para o fragmento com traduções para o português feitas em Portugal e no Brasil, expandindo-se a seguir o âmbito da comparação para incluir o francês, o espanhol e o italiano. É digno de nota que, dentre essas traduções, apena a italiana demonstra um esforço bem sucedido de recuperação melopáica.
\end{abstract} Palavras-chave: On the road; Transcriação; Melopeia; Jack Kerouac; Haroldo de Campos 


\title{
"WHEN THE SUN GOES DOWN": MELOPEIA AND TRANSCREATION IN JACK KEROUAC'S ON THE ROAD
}

\begin{abstract}
The purpose of the present work is to offer an actual transcreation of the final paragraph of Jack Kerouac's On the Road, which does preserve the intense melopoeia intrinsic in Kerouac's work, generally overlooked or ignored in most of its translations into other languages. To this end, the contributions to the theory of translation provided by Haroldo de Campos in numerous articles, essays and conferences over a period of forty years are mobilized herein. In fact, after a brief introduction to $\mathrm{On}$ the Road itself, a conceptual survey of Haroldo's thoughts on translation is presented, followed by the novel transcreation of Kerouac's book final paragraph, its comparison to both the Portuguese and the Brazilian extant Portuguese translations and then, expanding the comparative scope, also to the current French, Spanish and Italian translations of the same excerpt, of which the Italian one stands out as the only other translation containing a clear and effective effort of melopoeic recovery.
\end{abstract}

Key-words: On the road; Transcreation; Melopeia; Jack Kerouac; Haroldo de Campos.

\section{Para transcriar On the road}

Escrito inicialmente em 1951 e revisado múltiplas vezes até ser publicado em setembro de 1957, On the road foi o segundo livro de prosa de Kerouac (que viria a publicar mais uma dúzia em vida e outros tantos postumamente); com o passar do tempo, esse livro é cada vez mais reconhecido não só como a obra prima de Kerouac, mas também como o mais completo holótipo da prosa Beat, pois contém e aborda os temas existenciais e filosóficos caros àquela geração, sendo escrito como prosa "espontânea" (o que, na verdade, é uma ficção dentro da ficção), pois incorpora uma preocupação micrológica com a musicalidade do texto (uma batida algo jazzística) ao mesmo tempo em que tem o jazz como personagem e assunto, entremeado às estórias que conta e cuja veracidade factual é, e no todo, completamente irrelevante. Olhado dessa forma, o livro situa-se na tênue linha que divide a prosa da poesia, ainda que este 
aspecto do trabalho de Kerouac costume ser ignorado em prol da pura leitura linear de uma simples narrativa de estórias de viagem.

Mais do que um livro de viagem, On the road de Kerouac é uma viagem pela linguagem, efusiva na construção de imagens, na plasticidade do discurso, marcada por muitas referências, entre elas, além do jazz - e também no que concerne ao fluxo da linguagem de modo mais específico - pelo Joyce de Finnegan's Wake ${ }^{l}$. $\mathrm{Na}$ aparente espontaneidade de tal fluxo, que é, de fato, recurso estético, o texto de Kerouac se desenvolve entre os acordes das palavras, dissonâncias, imagens, ruídos, "enchentes" que gradativamente engendram o relato, articulando-o.

O leitor desavisado pode tomar como espontaneidade o fluxo poético da narrativa, mas o seu desenvolvimento (desenvoltura) só é possível porque o autor tem pleno domínio da língua, tanto quanto o músico da jam session tem de seu instrumento, mas ao contrário deste, as inúmeras revisões feitas na obra mostram que o trabalho de Kerouac foi criar o "parecer espontâneo" e não a espontaneidade em si, trata-se, pois, de uma poética do rigor, consciente dos (des)limites da língua e da invenção. Ao mobilizar meios radicalmente inventivos do ponto de vista da expressão, On the road situa-se naquele ponto em que a multiplicidade do narrado, a recriação das cenas pelas palavras, a organização sintática, expedientes narrativos/poéticos, fônicos, a escolha lexical e todos eles orquestrados pela melopeia ${ }^{2}$, enfim, performatizam o relato

\footnotetext{
1 Segundo Haroldo de Campos há, no Finnegan's Wake, “uma rede renhida de efeito sonoros a ser mantida [na transcriação], entremeada de quiproquós, trocadilhos, malopropismos [...] entrecho fluvial”. Cf. Campos, Augusto de; Campos, Haroldo de. Panaroma do Finnegan's Wake. São Paulo: Perspectiva, 2001 , p. 28. Kerouac menciona Joyce muitas vezes, inclusive com citações em textos criativos. A nosso ver, porém, On the road está além de Joyce, porque o devora criticamente e a ele alia muitas outras referências criativas. O jazz, como se disse, é indubitavelmente uma delas.

${ }^{2}$ Seguindo Pound (1954: 25), entende-se aqui a melopeia: “wherein the word are charged, over and above their plain meaning, with some musical property, which directs the bearing or trend of that meaning [...] The melopeia can be appreciated by a foreigner with sensitive ear though he be ignorant of the language in which
} 
ele mesmo, soa como jam, sobretudo se lido em voz alta, mas é, por assim dizer, um improviso ensaiado, uma ficcionalização-jam.

Neste artigo, trilhando a seara apontada pelos poetas concretos acerca da tradução e, mais especificamente, por Haroldo de Campos em seus inúmeros ensaios e contribuições, apresenta-se a transcriação do último parágrafo de On the road, acompanhando-a de uma discussão crítico-teórica. O desafio de traduzir a obra instigou a criação de soluções formais para fazer falar a obra de Kerouac em nossa cultura, ou melhor, para fazer cantar/tocar a melopeia em português ${ }^{3}$.

O propósito não é, portanto, esgotar a obra toda, mas ao pinçar um dos trechos mais poéticos do livro, seu parágrafo final. Seguindo a lição concretista da tradução como laboratório de textos, procura-se dar a ver o caleidoscópio de imagens e a jazz sinfônica que a tradução criativa pode (e deve) explorar em sua abordagem. Como bem aponta Haroldo de Campos, quanto maior a impossibilidade de tradução devido aos expedientes criativos e formais do texto de partida, tanto maior a possibilidade de recriação do mesmo (Campos, (a) 4). ${ }^{4}$ Diz Haroldo:

A tradução de poesia (ou prosa que a ela equivalha em
problematicidade) é antes de tudo uma vivência interior do
mundo e da técnica do traduzido. Como que se desmonta
e remonta a máquina da criação, aquela fragílima beleza
aparentemente intangível que nos oferece um produto aca-
bado numa língua estranha. E que, no entanto, se revela
suscetível de uma vivisseção implacável, que lhe revolve as

the poem is written. It is practically impossible to transfer or translate it from one language to another, save perhaps by divine accident, and for a half a line at a time".

${ }^{3}$ Agradeço a S. Jill Levine, Clayton Eshleman, Alexandre M. Roma e Eric Rieser pelas iluminadoras discussões, que muito contribuíram para a transcriação aqui apresentada (I. P. A. Campos)

${ }^{4}$ Utilizamos aqui Haroldo de Campos: transcriação", organizado por Marcelo Tápia e Thelma Médici Nóbrega e publicado pela editora Perspectiva (2013), em que se reúnem muitos dos mais relevantes ensaios de Haroldo sobre o tema. 
entranhas, para trazê-la novamente à luz num corpo linguístico diverso. (Campos, H. (a) 14)

A prosa de Kerouac, especificamente, a prosa de On the road, coloca-se como um desafio a essa "vivissecção implacável" ${ }^{5}$, ideia que está associada à concepção benjaminiana de tradução ${ }^{6}$. Conforme o próprio Haroldo, Benjamin estabelece que o tradutor deve alargar sua língua em lugar de preservá-la do choque, transferindo a preocupação com a fidelidade para a liberdade da tarefa de traduzir (Campos, (b) 103).

Entretanto, se para Benjamin a função do tradutor é angélica, ou seja, relaciona-se à tarefa (dívida, se quisermos falar com Derrida de Torres de Babel (2002)) de restituir ao original à língua pura, com liberdade criativa e sem o cerceador compromisso com a fidelidade, para Haroldo de Campos, o tradutor executa uma hybris luciferina, por isso mesmo, ameaça o original com a ruína, transformando “[...] por um átimo, o original na tradução de sua tradução; [para] reencenar a origem e a originalidade através da 'plagiotropia', como movimento incessante da 'diferença' [...]" (Campos, (c) 154, aspas do autor). Em outras palavras, e retomando a metáfora da vivissecção, a transcriação é "a reinstituição do corpo na tradução" (vivissecção) (Campos, (a) 105), e almeja, fausticamente, a "fragílima beleza" (Campos, (a), op.cit.), a intimidade do corpo do original da qual se apropria não apenas pela escuta da melopeia, mas pelos recônditos da epiderme do original, de sua pele de palavras que se abre para a dissecação: ruína por um turno; rútilo por outro, a dialética da transcriação lucifera. Nesse espectro, a dissecação não pode ser entendida como sacrificial, ao contrário, se é luciferina a operação,

\footnotetext{
${ }^{5}$ Vivissecção refere-se à dissecação de um animal vivo. O debate em torno da ética da prática é amplo. Aqui cabe notar justamente a importância da escolha lexical para Haroldo. O corpo a ser traduzido está vivo, pulsa e a transcriação, implacável, fará com que venha à luz em um corpo diverso.

6 "Die Aufgabe des Übersetzers", que se pode ler no original e em português em: Branco, Lucia Castello (2008). Disponível em: http://escritoriodolivro.com.br/ bibliografia/Benjamin.pdf. Acesso em 04/07/2019.
} 
é portadora de luz, o revolver do traduzido faz suas entranhas estranharem o comum, aceitando que a fidelidade é da ordem do imponderável, o conteúdo em si importa menos do que o facho de luz que a transcriação liberará, para se enovelarem num corpo diverso, livre e, ao mesmo tempo, libertador:

\begin{abstract}
O momento luciferino é apenas a rubrica metafórica dessa operação de finitização da metafísica benjaminiana do traduzir, para convertê-la numa física, num saber humano resgatado da subserviência hierática a um original 'aurático', liberado do horizonte teológico da língua pura, restituído ao campo cambiante do provisório (Campos, (d) 57)
\end{abstract}

A transcriação é um gesto intervalar. Não diz respeito nem ao original nem ao traduzido, mas se concretiza na invenção (na iluminação, se quisermos, dá a ver os diálogos culturais, a ampliação e reinvenção dos horizontes de leitura do texto transcriado. Há, portanto, uma constante tensão, um ir e vir, sem origem definida; o trabalho do tradutor constitui-se num eterno desconstruir, derridianamente falando, pois as possibilidades de reproposição dos signos do original são múltiplas. Vejamos como se comporta, então, a portabilidade da luz no excerto de On the road transcriado a seguir, cotejando, quando for pertinente, a proposta tradutória com as demais, feitas para outros idiomas.

\footnotetext{
${ }^{7}$ Aqui Haroldo associa a língua pura à aura. Isso pode causar estranhamento já que é o mesmo Benjamin quem falará da perda da aura. Foge do escopo do artigo entrar no mérito dessa discussão, cumpre apenas destacar que neste mesmo ensaio citado acima, Haroldo adverte o leitor para a postura ambígua de Benjamin em relação à destruição da aura pela experiência do choque. Entendemos aqui que o choque, de fato, pela tradução, acontece quando esta é realizada enquanto operação luciferina.
} 


\section{A insurgência melopaica}

André Bretton escreveu em Nadja "la beauté sera CONVULSIVE ou ne sera pas" (160) Acreditamos que vale a pena uma livre apropriação do aforismo conhecido para propor: A melopeia ou será insurgente ou não será, uma vez que justamente por nascer da profusão, da festa significante, encena mais do que a língua de partida, no caso de On the road, encena a linguagem pulsante da viagem em si. Reside aí a força motriz da linguagem de dessa obra e acreditamos que, diante da impossibilidade de traduzir a prosa/ poesia, a solução chega pela via da escuta e do tato: ouvir a melopeia, tocar a pele do texto para notar seu volume, sua densidade, seu movimento.

Amparados pelo que foi discutido até aqui, pode-se analisar o parágrafo final do livro, pela via da tradução, entendendo-a como crítica. Esse parágrafo pode ser lido isoladamente e ao mesmo tempo é um excelente representante do que foi feito pelo autor ao longo da obra. A análise se torna ainda mais relevante quando inclui também várias traduções (tanto em outras línguas latinas como uma inédita só do parágrafo final (P.I), de forma a evidenciar e ressaltar a leitura que dele fizeram os vários tradutores. Vejamos então o fragmento e nossa proposta transcriativa:

So in America when the sun goes down and I sit on the old broken-down river pier watching the long, long skies over New Jersey and sense all the raw land that rolls in one unbelievable huge bulge over to the West Coast, and all that road going, all the people dreaming in the immensity of it, and in Iowa I know by now the children must be crying in the land where they let children cry, and tonight the stars'll be out, and don't you know that God is Pooh Bear? the evening star must be drooping and shedding her sparkler dims on the prairie, which is just before the coming of complete night that blesses the earth, darkens all rivers, cups the peaks and folds the final shore in, and nobody, nobody knows 
what's going to happen to anybody besides the forlorn rags of growing old, I think of Dean Moriarty, I even think of Old Dean Moriarity the father we never found, I think of Dean Moriarity (Kerouac 191)

\section{Tradução para o Português I $(\mathrm{PI})^{8}$ :}

Então, quando me sento no velho e carcomido cais do rio, olhando o céu sem-fim sobre New Jersey, o sol se pondo sobre a América, eu sinto toda aquela terra nua como um enorme e vertiginoso arco que segue para a costa oeste, tanta estrada indo, tanta gente sonhando nessa imensidão e eu sei que agora em Iowa as crianças estão chorando, na terra em que ninguém liga prá isso, e esta noite vai ter estrelas no céu e você já não sabe que Deus é o Ursinho Puff? Venus já vai se pondo, vertendo seu brilho pálido na pradaria, logo antes de cair de vez a noite, que abençoa a terra, escurece os rios, encobre os montes e envolve a praia lá no fim, e ninguém, ninguém nada sabe sobre o futuro de ninguém, senão pelos frios farrapos de ficar velho, eu penso em Dean Moriarty, eu até mesmo penso no velho Dean Moriarty, o pai que a gente sempre quis ter, eu penso em Dean Moriarty (Campos, I. [mimeo]).

So in America when the sun goes down and I sit on the old brokendown river pier watching the long, long skies over New Jersey and...

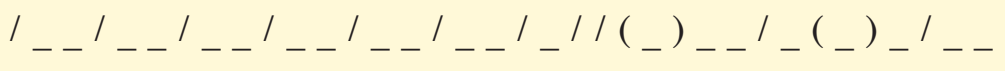

O trecho é composto em dátilos, meditativos e melancólicos, “quebrados" em alguns pés - como não o faria a tradição poéti-

${ }^{8}$ Como há três traduções para o português, as mesmas serão indicadas por PI; PII; PIII. 
ca, mas a prosa; além disso, uma oralização coloquial conduz a “when'e”, “brok'n” e “th'long”. Outras leituras são possíveis (mas menos prováveis): a prosa é mais flexível que a tradição estritamente poética; seja qual for a leitura, o ritmo do texto é facilmente "audível", assim como seu "eco»psicológico", figurando o cais em ruínas. A escansão rítmica aparece claramente entre "pier” e "watching", justamente no ponto-chave do texto, onde o autor declara sua (in)ação frente à paisagem baldia. Kerouac semantiza seu texto através do ritmo como o fazem poucas prosas. A tarefa do tradutor é complicada pelos "engenhos poéticos" contrastados das línguas. Enquanto o inglês se move naturalmente na tradição rítmica greco-latina, o português (e as demais línguas latinas) é oficialmente uma língua "quantitativa", na esteira do francês, em que mais importa o número de sílabas que sua acentuação... ainda que, ao nosso ver, esta medida possa - e deva - ser associada a esquemas rítmicos tradicionais (mas discutir aqui este ponto transcende o escopo do presente trabalho).

Vejamos o resultado obtido na tradução inédita aqui apresentada: inicialmente existe a questão do "in America", que abre o trecho final no original (por razões evidentemente fônicas), tendo sido preservado nessa mesma posição em todas as traduções aqui reproduzidas (conferir no anexo as traduções), exceto em P.I.. A manutenção desta posição cria um problema de disfonia nessas línguas latinas (menos notável em italiano, onde é possível ler "Cosi'n” (cf. anexo)), e, por esta razão, qual seja, a da manutenção da preocupação melopaica, optou-se, na P.I, por movê-lo para longe do começo do trecho.

Então, quando me sento no velho e carcomido cais do rio, olhando o céu sem-fim sobre New Jersey, o...

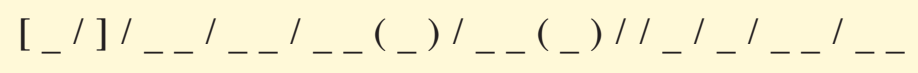

A manutenção do então (na tradução de "so") favorece as escolhas lexicais seguintes, assinaladas em negrito acima, que buscam, justamente, um ritmo tão análogo quanto possível ao original. Evi- 
dentemente, seria arriscado dizer que se respondeu, inicialmente, "dátilo a dátilo" ao original, já que o português não apresenta sílabas longas e breves (ainda que as possua tônicas e átonas); quanto aos dois "peônios" subsequentes (uma longa, três breves), pode-se também oralizá-los como "dátilos": "carc'mido", "d'rio". Desse modo, trata-se de buscar alcançar um esquema rítmico que resgate, da melhor forma possível, aquele do original, guardadas também as diferenças de construção rítmica e métrica de cada uma das línguas. A escansão ocorre exatamente no mesmo ponto, com o mesmo relevo semântico destacando a (in)ação do narrador. Os dois "iambos" seguintes tornam o "céu sem-fim" um correlato insistente e premonitório da desolação por vir. O resultado é interessante, sobretudo se comparado às soluções anteriores, em português. Em P.II tem-se:

Assim, na América, quando o sol se põe e me sento no velho molhe desmoronado do rio a contemplar os céus infindáveis por cima de New Jersey e...(Rodrigues; Gato 403)

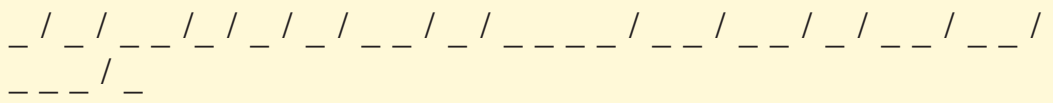

Trata-se de prosa corrida, sem preocupação aparente com o ritmo do original, mesmo que se leve em conta as vogais átonas instáveis, tão mais presentes no português de Portugal (vale notar que sua maior ou menor instabilidade não é a mesma ao longo desse país europeu). É, também, particularmente notável a presença do eco cacofático em “desmoronado do rio". Na tradução de Eduardo Bueno tem-se:

Assim, na América, quando o sol se põe e eu sento no velho e arruinado cais do rio olhando os longos, longos céus acima de Nova Jersey, e...(Bueno 372)

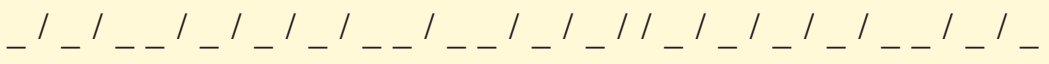


Temos, na P.III, outro exemplo claro de prosa corrida, em que predomina a batida binária "básica" do português brasileiro coloquial. A escansão marcada pelas duas tônicas subsequentes ocorre no lugar "certo", mas quase por acidente: o "olhando" segue a cena "por acaso": a (in)ação não é carregada semanticamente como no primeiro caso. Neste ponto, cabe notar que a ausência de vírgulas no longo trecho que sucede "na América" em PII e PIII, ainda que, possivelmente, fruto de um deliberado o esforço do tradutor para recuperar a "oralidade" do texto, acaba por esvaziar-se em virtude da escassez de paranomásias que mais contundentemente assegurariam o ritmo.

Nas traduções para o espanhol e para o italiano a musicalidade do texto, sua orquestração melopaica, em especial no que tange à nasalização, que constrói o sentido de fluxo, caminhada, da estrada que se abre jazzisticamente, perde força em alguns momentos pela escolha lexical distante da escuta da poesia ou mesmo do sentido irônico e afetivo do original, como é o caso da substituição de "Ursinho Puf" no italiano e no francês.

Cabe, portanto, uma observação "semântica": é importante preservar o Ursinho Puff, não substituí-lo pela Ursa Maior (à qual ele é associado em outro ponto do texto): isso representa a diferença entre a perspectiva de uma recordação/experiência infantil daquela de uma observação astronômica descarnada. Ora, se a passagem segue com uma descrição de paisagem, ela é justamente carregada de afeto, "emocionada", por este intróito... o desamparo das criancinhas chorando, descrito imediatamente antes, basta para esclarecer a necessidade de se manter o "ursinho", não a "ursona".

Desse modo, as demais traduções consideradas, voltando-se principalmente para o sentido do texto e menos para sua forma; todavia as rimas (quase que incontornáveis diante da força do original) se fazem presentes e se não garantem a melopeia, asseguram em diferentes graus, um movimento muito curioso em que o original luciferinamente impõe seu facho de luz (ou mesmo uma tênue lanterna tímida) ao traduzido9:

${ }^{9}$ A discussão extrapola os limites do artigo, mas faz pensar que o original 
Así, en esta América, cuando se pone el sol y me siento en el viejo y destrozado malecón contemplando los vastos, vastísimos cielos de Nueva Jersey y se mete en mi interior toda esa tierra descarnada que se recoge en una enorme ola precipitándose sobre la Costa Oeste, y todas esas carreteras que van hacia allí, y toda la gente que sueña en esa inmensidad, y sé que en Iowa ahora deben estar llorando los niños en la tierra donde se deja a los niños llorar y esta noche saldrán las estrellas (¿no sabéis que Diós es el osito Pooh?) (Lendínez 363-364 ).

Così in America quando il sole va giù e io siedo sul vecchio diroccato molo sul fiume a guardare i lunghi, lunghissimi cieli sopra il New Jersey e avverto tutta quella terra nuda che si svolge in un'unica incredibile enorme massa fino alla Costa Occidentale, e tutta quella strada che va, tutta la gente che sogna nell'immensità di essa, e so che nello Iowa a quell'ora i bambini stanno certo piangendo nella terra in cui lasciano piangere i bambini, e che stanotte usciranno le stelle, e non sapete che Dio è l'Orsa Maggiore? (Cristofaro 311)

$\mathrm{Na}$ tradução francesa, a sonoridade da língua favorece a nasalização, mas o ritmo truncado, ainda que consideradas as paronomásias, revela-se menos potente do que a proposta italiana, por exemplo, e do que a nossa:

en Amérique, quand le soleil descend et que je suis assis près du fleuve sur le vieux quai démoli, contemplant au loin, très loin, le ciel au-dessus du New-Jersey, et que je sens tout ce pays brut rouler en bloc son étonnante panse géante jusqu'à la Côte Ouest et toute cette route qui y va, tous ces gens qui rêvent dans son immensité - et, dans l'Iowa, je le sais, les enfants à présent doivent être en train

(sobretudo quando poético) tem uma força que acaba por invadir a tradução, de tal sorte que as escolhas do tradutor, mesmo que em grau reduzido, ver-se-ão amalgamadas à função poética que percorre o corpo original.

Cad. Trad., Florianópolis, v. 40, ${ }^{0}{ }^{1}$, p. 127-146, jan-abr, 2020. 
de pleurer dans ce pays où on laisse les enfants pleurer, et cette nuit les étoiles seront en route et ne savez-vous pas que Dieu c'est le Grand Ours et l'homme-orchestre? (Houbart, 1960, p.479)

Como se observa, quanto aos excertos em outras línguas, a tradução para o espanhol, com seu discurso impetuoso (vide a "enorme onda que se precipita à Costa Oeste", algo como a diferença entre o toureiro defronte seu miura e um andarilho que chega ao fim da estrada...), apresenta um ritmo interessante, mas ainda bem preso à prosa corrida. Já a tradução italiana, justíssima, tem o achado de "stillicidio" (como a água que goteja de um muro carcomido) para os "forlorn rags"... e é a única, além da P.I, que demonstra clara preocupação com o ritmo e o "espírito" geral do texto. A tradução francesa, por outro lado consegue a façanha de misturar a pomposidade de certo francês literário com imagens grotescas, como "je sens tout ce pays brut rouler en bloc son étonnante panse géante" ("sinto toda esta terra bruta virar em conjunto sua espantosa pança gigante"), e além, "n'étaient les mornes misères de l'âge qu'on prend" ("não fo$\mathrm{ram} /$ fossem [imperfeito indicativo empregado, no texto, como subjuntivo: forma excessivamente literária, no contexto] as deprimentes misérias da idade que se acumula")... sem falar no "Grande Urso", quando se trata, claramente, de um «ourson» (ursinho).

Voltando à tradução P.I, cabe ressaltar a concisão do texto, que embora obtida nas outras traduções, ganha força se somada aos expedientes de conncisão adotados, com o objetivo de preservar ao máximo o ritmo original, observando sempre a importância do caráter icônico do texto de partida e transportando-o ao de chegada, o que equivale à recriação da fisicalidade do original (Campos (b) 85) também. Enfim, aqui, o resgate da melopeia, presente no texto de Kerouac foi realizado também por um espelhamento semântico quase palavra-a-palavra. Outras escolhas, menos literais, teriam sido possíveis, desde que atentas ao aspecto melódico do texto original, que precisa ser preservado, caso se queira permitir ao leitor uma experiência análoga à que tem o leitor do original. 


\section{Considerações Finais: On the road rebabelizada}

Se em Benjamin havia a expectativa da emergência da língua pura pela via tradutória, língua aurática, que desbabelizaria original e tradução, pela redenção/ anunciação angelical, a transcriação luciferina, ao jogar com o provisório, o cambiante, o lance de dados do imponderável, cria ainda uma língua outra, que não é a de partida, tampouco a de chegada - como o seria em uma tradução pautada pela fidelidade; é a língua de chegada marcada pelas cicatrizes (ruínas) e pelas floradas (rútilos) da língua do texto original. Sob essa perspectiva, a transcriação, ou seja, a tradução poética em amplo sentido, não se coloca como uma tentativa de desbabelização, de retorno a um estado original em que a "língua de verdade" revigora, mas, antes, é a re-babelização de uma língua em trânsito, em que as culturas rasuram fronteiras, em que as experiências transitam entre corpos diversos e em que o que há de humano na linguagem se eleva à potencia máxima, aquela que só a poesia, pensada aqui em amplo espectro, reinstitui e funda outra realidade da linguagem, pautada pela mistura, pelo gesto antropofágico que une ambos os idiomas e resulta, portanto, em uma língua que se não teme o estranhamento do original em si mesma, também não concede a ele primazia. Por isso mesmo, nosso propósito foi explicitar como a transcriação P.I do último parágrafo de On the road rebabelizou a estrada, fez dançar o sol, o céu sem fim, os farrapos, emprestando e devolvendo com juros a melopeia.

A ur-língua que daqui emerge não é, pois, uma língua primordial e pura, mas aquela que atravessando a inóspita jornada dos inexoráveis, dos indecidíveis do inglês e do português funda o trânsito, o diálogo. É por isso que, para Haroldo de Campos, a tradução é a força pós-utópica por excelência, é ela quem viabiliza a poética da agoridade que no lugar de um princípio-esperança, tendente ao futuro paradisíaco, como paradisíaca talvez seja a língua pura benjaminiana, volta-se para o princípio realidade, faz conversar no aqui-agora da transcriação e, a partir dele, permanentemente, 
corpos que antes dela não podiam conversar; torna-os habitáveis, críticos, transumaniza-os, luciferinamente.

\section{Referências}

Branco, Lucia Castello (org) "A tarefa do tradutor" para Walter Benjamin em quarto traduções para o português. Belo Horizonte: Fale/UFMG, 2008.

Bretton, Andre. Nadja. Paris: Galimard, 1964, p.160.

Campos, Haroldo de. "Da tradução como teoria e como crítica,". In: Tápia, Marcelo; Nóbrega, Thelma Médici (org). Haroldo de Campos- transcriação. São Paulo: Perspectiva, 2013a, p. 1-19.

Campos, Haroldo de. "Da transcriação: poética e semiótica da operação tradutora”. In: Tápia, Marcelo; Nóbrega, Thelma Médici (org). Haroldo de Campos- transcriação. São Paulo: Perspectiva, 2013b, p. 77-104

Campos, Haroldo de. "O que é mais importante: a escrita ou o escrito: teoria da linguagem em Walter Benjamin”, In: Tápia, Marcelo; Nóbrega, Thelma Médici (org). Haroldo de Campos- transcriação. São Paulo: Perspectiva, 2013c, p. 141154.

Campos, Haroldo de. "Para além do princípio da saudade: a teoria benjaminiana da tradução". In: Tápia, Marcelo; Nóbrega, Thelma Médici (org). Haroldo de Campos- transcriação. São Paulo: Perspectiva, 2013d, p.47-60.

Campos, Haroldo de. "À esquina da esquina". In: Tápia, Marcelo; Nóbrega, Thelma Médici (org). Haroldo de Campos- transcriação. São Paulo: Perspectiva, 2013e, p.105-107. 
Derrida, Jacques. Torres de Babel. Tradução: Junia Barreto. Belo Horizonte: EDUFMG, 2002

Kerouac, Jack. On the Road, (1 ${ }^{\mathrm{a}}$. ed, 1957), New York: Penguin, 1983, p. 291.

Kerouac, Jack. Pela Estrada Fora. Tradução de A. Rodrigues e M. Vale de Gato (1 ${ }^{\text {a }}$. ed, 1998). Lisboa: Relógio de Água, 1998(a), p. 403.

Kerouac, Jack. Pé na Estrada. Tradução de E. Bueno (1 ${ }^{\mathrm{a}}$. ed, 1984)Porto Alegre: LP\&M, 2004(b), p. 372.

Kerouac, Jack. En el Camino. Tradução de M. Lendínez (1 ${ }^{\text {a }}$. ed, 1986).Barcelona: Anagrama, 2004(c), p. 363-364.

Kerouac, Jack. Sulla Strada. Tradução de M. M. de Cristofaro (1 ${ }^{\text {a }}$. ed, 1959). Milão: Mondadori, 2008(d), p. 311.

Kerouac, Jack. Sur la Route. Tradução de J. Houbart ( ${ }^{\mathrm{a}}$. ed, 1960) Paris: Gallimard, 1997(e), p.479.

Pound, Ezra. Literary Essays of Ezra Pound. Edited by T.S. Eliot. London: Faber, 1954.

Recebido em: 01/09/2019

Aceito em: 10/12/2019 Publicado em janeiro de 2020

Diana Junkes. E-mail: dijunkes@ufscar.br

ORCID: https://orcid.org/0000-0002-5465-8030

Luiz Carlos de Brito Rezende. E-mail: Luiz_Rezende_BR@hotmail.com ORCID: https://orcid.org/0000-0003-2457-0668

Ivan Pérsio de Arruda Campos. E-mail: ipdacamp@uol.com.br

ORCID: https://orcid.org/0000-0002-7967-7297 


\section{ANEXO}

\section{Jack Kerouac, On the Road, Parte V, Parágrafo Final}

So in America when the sun goes down and I sit on the old broken-down river pier watching the long, long skies over New Jersey and sense all the raw land that rolls in one unbelievable huge bulge over to the West Coast, and all that road going, all the people dreaming in the immensity of it, and in Iowa I know by now the children must be crying in the land where they let children cry, and tonight the stars'll be out, and don't you know that God is Pooh Bear? the evening star must be drooping and shedding her sparkler dims on the prairie, which is just before the coming of complete night that blesses the earth, darkens all rivers, cups the peaks and folds the final shore in, and nobody, nobody knows what's going to happen to anybody besides the forlorn rags of growing old, I think of Dean Moriarty, I even think of Old Dean Moriarity the father we never found, I think of Dean Moriarity.

\section{Traduções para o Português: (P.I) de Ivan P. de Arruda Campos, 2005}

Então, quando me sento no velho e carcomido cais do rio, olhando o céu sem-fim sobre New Jersey, o sol se pondo sobre a América, eu sinto toda aquela terra nua como um enorme e vertiginoso arco que segue para a costa oeste, tanta estrada indo, tanta gente sonhando nessa imensidão e eu sei que agora em Iowa as crianças estão chorando, na terra em que ninguém liga prá isso, e esta noite vai ter estrelas no céu e você já não sabe que Deus é o Ursinho Puff? Venus já vai se pondo, vertendo seu brilho pálido na pradaria, logo antes de cair de vez a noite, que abençoa a terra, escurece os rios, encobre os montes e envolve a praia lá no fim, 
e ninguém, ninguém nada sabe sobre o futuro de ninguém, senão pelos frios farrapos de ficar velho, eu penso em Dean Moriarty, eu até mesmo penso no velho Dean Moriarty, o pai que a gente sempre quis ter, eu penso em Dean Moriarty.

\section{(P.II) de Armanda Rodrigues e Margarida Vale de Gato, 1998}

Assim, na América, quando o sol se põe e me sento no velho molhe desmoronado do rio a contemplar os céus infindáveis por cima de New Jersey e tenho a percepção de toda aquela terra bruta que rola num único bojo enorme e incrível até à Costa Oeste, e toda aquela estrada a avançar, todas as pessoas que sonham na sua imensidão, e sei que a esta hora, no Iowa, as crianças devem estar a chorar na terra em que deixam as crianças chorar, e esta noite as estrelas serão visíveis, e não sabem que Deus é o Urso Pooh? a estrela vespertina deve estar a curvar-se e a irradiar a sua pálida claridade cintilante sobre a pradaria, o que acontece mesmo antes do cair da noite completa que abençoa a terra, escurece todos os rios, dá a forma de concha aos cumes e envolve a derradeira margem, e ninguém, ninguém sabe o que vai suceder seja a quem for, além dos trágicos farrapos do envelhecer, penso em Dean Moriarty; penso até no Velho Dean Moriarty, o pai que não chegámos a encontrar, penso em Dean Moriarty.

\section{(P.III) de Eduardo Bueno, 1984}

Assim, na América, quando o sol se põe e eu sento no velho e arruinado cais do rio olhando os longos, longos céus acima de Nova Jersey, e posso sentir toda aquela terra rude se derramando numa única, inacreditável e elevada vastidão até a Costa Oeste, e toda aquela estrada seguindo em frente, todas as pessoas sonhando nessa imensidão, e em Iowa eu sei que agora as crianças devem estar chorando na terra onde deixam as crianças chorar, e essa noite as estrelas vão aparecer, e você não sabe que Deus é a Ursa Maior? 
E a estrela do entardecer deve estar morrendo e irradiando sua pálida cintilância sobre a pradaria antes da chegada da noite completa que abençoa a terra, escurece todos os rios, recobre os picos e oculta a última praia e ninguém, ninguém sabe o que vai acontecer a qualquer pessoa, além dos desamparados andrajos da velhice, eu penso em Dean Moriarty; penso até no velho Dean Moriarty, o pai que jamais encontramos; eu penso em Dean Moriarty.

\section{Tradução para o Espanhol de Martín Lendínez, 1986}

Así, en esta América, cuando se pone el sol y me siento en el viejo y destrozado malecón contemplando los vastos, vastísimos cielos de Nueva Jersey y se mete en mi interior toda esa tierra descarnada que se recoge en una enorme ola precipitándose sobre la Costa Oeste, y todas esas carreteras que van hacia allí, y toda la gente que sueña en esa inmensidad, y sé que en Iowa ahora deben estar llorando los niños en la tierra donde se deja a los niños llorar, y esta noche saldrán las estrellas (¿no sabéis que Diós es el osito Pooh?), y la estrella de la tarde dedicará sus mejores destellos a la pradera justo antes de que sea totalmente de noche, esa noche que es una bendición para la tierra, que oscurece los ríos, se traga las cumbres y envuelve la orilla del final, y nadie, nadie sabe lo que le va a pasar a nadie excepto que todos seguirán desamparados y haciéndose viejos, pienso en Dean Moriarty, y hasta pienso en el viejo Dean Moriarty, ese padre al que nunca encontramos, sí, pienso en Dean Moriarty.

\section{Tradução para o Italiano de Magda Maldini de Cristofaro, 1959}

Così in America quando il sole va giù e io siedo sul vecchio diroccato molo sul fiume a guardare i lunghi, lunghissimi cieli sopra il New Jersey e avverto tutta quella terra nuda che si svolge in un'unica incredibile enorme massa fino alla Costa Occidentale, e tutta quella strada che va, tutta la gente che sogna nell'immensità 
di essa, e so che nello Iowa a quell'ora i bambini stanno certo piangendo nella terra in cui lasciano piangere i bambini, e che stanotte usciranno le stelle, e non sapete che Dio è l'Orsa Maggiore?, e la stella della sera deve star tramontando e spargendo il suo fioco scintillìo sulla prateria, il che avviene proprio prima dell'arrivo della notte completa che benedisce la terra, oscura tutti i fiumi, avvolge i pichi e rimbocca le ultime spiagge, e nessuno, nessuno sa quel che succederà di nessun altro se non il desolato stillicidio del diventar vecchi, allora penso a Dean Moriarty, penso persino al vecchio Dean Moriarty, il padre che mai trovammo, penso a Dean Moriarty.

\section{Tradução para o Francês de Jacques Houbart, 1960}

Ainsi donc, en Amérique, quand le soleil descend et que je suis assis près du fleuve sur le vieux quai démoli, contemplant au loin, très loin, le ciel au-dessus du New-Jersey, et que je sens tout ce pays brut rouler en bloc son étonnante panse géante jusqu'à la Côte Ouest et toute cette route qui y va, tous ces gens qui rêvent dans son immensité - et, dans l'Iowa, je le sais, les enfants à présent doivent être en train de pleurer dans ce pays où on laisse les enfants pleurer, et cette nuit les étoiles seront en route et ne savez-vous pas que Dieu c'est le Grand Ours et l'homme-orchestre? et l'étoile du berger doit être en train de décliner et de répandre ses pâles rayons sur la prairie, elle que vient juste avant la nuit complète qui bénit la terre, obscurcit tous les fleuves, décapite les pics et drape l'ultime rivage et personne, personne ne sait ce qui va arriver à qui que ce soit, n'étaient les mornes misères de l'âge qu'on prend - alors je pense à Dean Moriarty, je pense même au Vieux Dean Moriarty, le père que nous n'avons jamais trouvé, je pense à Dean Moriarty. 